\title{
DETERMINAÇÕES DE SÓLIDOS SOLÚVEIS E QUALI- DADE DA BEBIDA EM AMOSTRAS DE CAFÉ DOS PORTOS BRASILEIROS DE EXPORTAÇÃO ${ }^{1}$
}

Ruth dos Santos Garruti, Cyro Gonçalves TelXeira, engenheiros-agrônomos, Secção de Tecnologia Agrícola, OdeTE Z. DE TOLEDo, engenheiro-agrônomo, Secção de Viticultura, e JoAssy de Paula Neves Jorge, licenciada em matemática, Seção de Técnica Experimental, Instituto Agronômico.

\section{RESUMO}

O presente trabalho relato resultados de determinações de sólidos solúveis e qualidade da bebida em amostras de café, procedentes dos portos brasileiros de exportaçăo. Nas determinações, foram utilizados métodos específicos, padronizados no instituto Agronômico.

A moior porcentagem de sólidos solúveis foi observada no produto do Estado de Minas - Zona Sul do Estado. Quanto à qualidade da bebida, o café despolpado da Zona da Mata, de Minas Gerais, alcançou melhor bebida - mole - diferindo, significativamente, das demais, ao nível estatístico de 5\%. A pior bebida observada foi ainda do Zona da Mata do Estado de Minas Gerais - bebida rio bem como na Zona Oeste de Minas - bebida riada - em cafés não despolpados.

Não foi observada nenhuma reloção entre qualidade da bebida e porcentogem de sólidos solúveis, nas amostras de cofé estudadas.

\section{1 - INTRODUÇÃO}

A indústria de café solúvel tem tido grande incremento nus países tradicionalmente consumidores de café. Apresenta duas grandes vantagens: a) fácil e rápido preparo da bebida, reduzindo as perdas que se verificam pelo preparo tradicional; $b$ ) menor despesa de transporte, em virtude da redução do volume.

Além disso, sendo o café solúvel acondicionado em latas ou vidros hermèticamente fechados, possivelmente em atmosfera de gás inerte, conserva melhor suas qualidades.

Entretanto, para a obtenção de um café solúvel de boa qualidade, que venha encontrar aceitação por parte do público consumidor, será

1 Recebido para publicaçăo em 18 de maio de 1961. 
necessário utilizar, como matéria prima, cafés bem preparados, colhidos convenientemente e que apresentem tôdas as características de boa bebida.

Do ponto de vista econômico, para a indústria de solúvel, tornase aconselhável que o café empregado na industrializaçāo, além de boo qualidade, apresente teor elevado em sólidos solúveis, para aumentar o rendimento na produção. Foi o propósito do presente trabalho verificar, além da qualidade da bebida dos cafés provenientes dos diversos portos de exportação, o seu teor em sólidos solúveis, visto que as condições ideais para a produção de café solúvel seriam as que aliassem bebida de alta qualidade com elevado teor em sólidos
solúveis.

\section{2 - MATERIAL E MÉTODO}

Interessados em dados sôbre a quantidade de sólidos solúveis dos cafés que saem dos portos brasileiros de exportação e sua possível influência na qualidade da bebida, os autores entraram em entendimentos com o Instituto Brasileiro do Café, que prontamente Ihes enviou as amostras abaixo relacionadas:

N. DA AMOSTRA

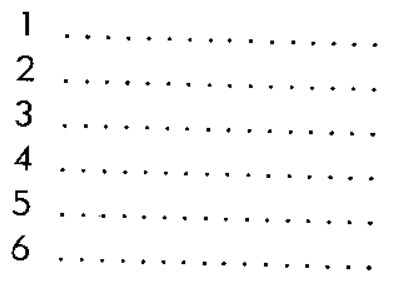

7

8

9

10

\section{Procedência}

Estado de Minas Gerais - Zona da Mata Estado de São Paulo

Estado do Paraná

Estado do Paraná - Paranaguá 3

Estado de Minas Gerais - Zona Sul

Estado de Minas Gerais - Zona da Mata, despolpado

Estado de Minas Gerais - Zona Oeste

Estado de Minas Gerais - Zona da Mata,

Estado do Paraná - - Paranaguá 1

Estado do Paraná — Paranaguá 2

Na determinação da porcentagem de sólidos solúveis empregou-se método aperfeiçoado nos laboratórios do Instituto Agronômico de Campinas (3). Os testes organolépticos foram efetuados por uma equipe treinada pelo Laboratório de Degustação do Instituto Agronômico para degustação de café. Os degustadores compareceram às 
provas duas vêzes ao dia. De acôrdo com o delineamento estatístico empregado, o número de repetições foi de seis, para cada amostra.

Foi escolhido um delineamento em blocos incompletos equilibrados, do tipo III, com 15 blocos, com quatro amostras por bloco (1), isto é, cada provador recebeu quatro xícaras para degustar. Na anólise estatística dos dados foi utilizada uma escala de valores adotada para ensaios de degustação de café (2).

As mesmas amostras, com repetições, foram enviadas oo Sr. José Camargo, provador da Secretaria da Agricultura, na Casa da Lavoura de Campinas, para comparação de resultados.

\section{3 - RESULTADOS}

Os dados sôbre as determinações de sólidos solúveis e qualidade da bebida se encontram no quadro 1 .

Quanto à porcentagem de sólidos solúveis, observou-se, através da análise da variôncia, que houve diferenças significativas, sendo estas calculadas pelo método de Tukey. O café do Sul de Minas apresentou maior porcentagem de sólidos solúveis $(27,31 \%)$, diferindo, significativamente, dos demais, ao nivel de $5 \%$. O de Paranaguá 2 alcançou a menor média $(25,06 \%)$, isto é, a menor porcentagem de sólidos solúveis.

$\mathrm{Na}$ determinação da qualidade da bebida, encontraram-se, igualmente, diferenças significativas entre as amostras. Usando as diferenças mínimas significativas (Tukey) para duas médias, concluiu-se que o café de Minos Gerais, Zona da Mata, despolpado, foi significativamente superior a todos os demais, ao nível de $1 \%$, acusando bebida mole, característica.

As amostras de São Paulo, Paranaguá 2 e 3, Paraná e Sul de Minas Gerais não diferiram, estatìsticamente, entre si, classificandose como bebida apenas mole. A amostra Paranaguá 1 alcançou média correspondente à bebida dura.. As duas amostras de café não despolpado do Estado de Minas Gerais, do Zona da Mata, alcançaram média correspondente à bebida rio, diferindo, ao nível de $1 \%$, do café Oeste de Minos, classificado como bebida riada.

Na quadro 1 também figuram os resultados da classificação efetuada na Casa da Lavoura de Campinas. Observa-se que êles diferem ligeiramente dos obtidos nos laboratórios do Instituto Agronô. mico, fato êsse que é atribuido à diferença de métodos empregados. 


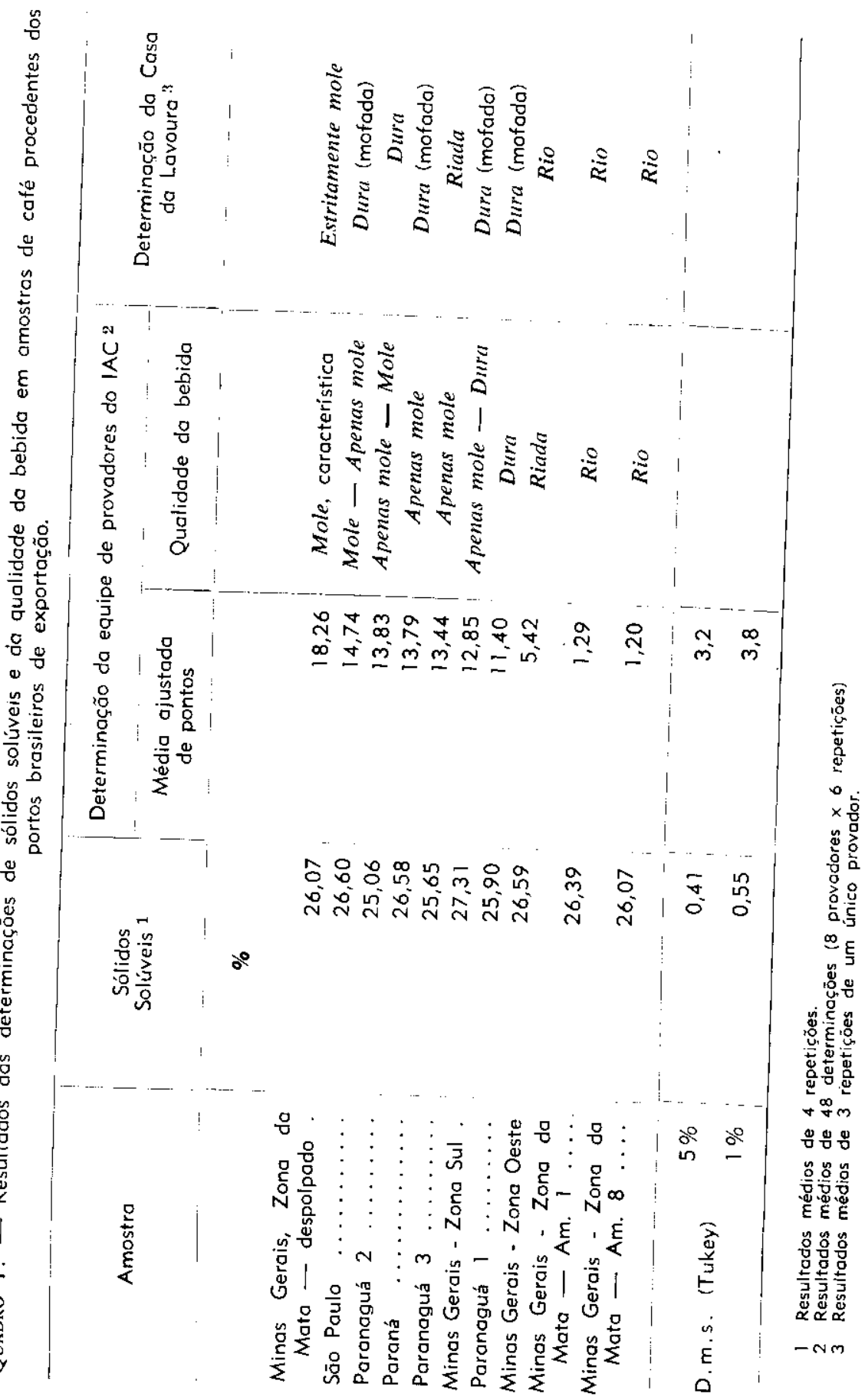




\section{4 - CONCLUSŌES}

As seguintes conclusões podem ser tiradas do presente estudo:

a) O café de Minas Gerais - Zona Sul - alcançou a maior porcentagem de sólidos solúveis $(27,31 \%)$, diferindo, significativamente, dos demais cafés.

b) Não houve relação entre teor de sólidos solúveis e qualidade da bebida.

c) Quanto à qualidade da bebida, encontraram-se nos produtos do Estado de Minas Gerais os melhores e os piores resultados: o café despolpado da Zona da Mata apresentou a meIhor bebida, quer para a equipe de provadores do Instituto Agronômico, com a especificação de mole característica, quer para o provador da Casa da Lavoura, com a classificação - estritamente mole.

d) O café da Zona Oeste de Minas Gerais e os não despolpados da Zona da Mata apresentaram as piores bebidas, ou seja bebida riada e rio respectivamente.

\section{DETERMINATIONS OF SOLURLE SOLIDS AND BEVERAGE QUALITY IN COFFEE SAMPLES FROM THE DIFFERENT BRAZILIAN EXPORT PORTS}

\section{SUMMARY}

The present experimental work reports the results of the determination of soluble solids and beverage quality in coffee samples received from the Brazilian Coffee Institute. The samples originated from different coffee zones and were collected in the Brazilion export ports warehouses. Specific methods developed ot the Instituto Agronômico were applied in both determinations. The data were stotistically analysed and showed highly significant results. The highest percentage in soluble solids referred to a coffee sample from the south region of the state of Minos Gerais. The best beverage was obtained from a pulped coffee sample prepared in the so-called "Zona da Mato" of the state of Minas Gerais, which was statistically different from the others at the $5 \%$ level. The beverages of low quality corresponded to a Rio coffee flavor sample from the so-called "Zona da Mato" and onother one with "slightly Rio flavor" from the west of the state of Minas Gerais.

No relation was found between beverage quality and soluble solids percentage in the different coffee somples. 


\section{LITERATURA CITADA}

1. COCHRAN, W. G. \& COX G. M. Experimental Designs. 2.a Edição. New York, John Wiley \& Sons, Inc., 1957. 611 p.

2. GARRUTI, R. S. \& CONAGIN, A. Escalo de valores pora avaliação da qualidade da bebida do café. Bragantia 20:[555]-560. 1961.

3. TOLEDO, O. Z., TEIXEIRA, C. G. \& GARRUTI, R. S. Sólidos solúveis em progênies e variedades de café. Boletim da Superintendência dos Serviços do Cofé. [No prelo] 